\title{
Amplificação gênica alelo-específica na caracterização das hemoglobinas S, C e D e as interações entre elas e talassemias beta
}

\author{
Allele-specific genic amplification in the characterization of hemoglobins $S, C, D$ and \\ interactions among them and with beta thalassemia
}

Luciane Cristina Bertholo1, Haroldo Wilson Moreira²

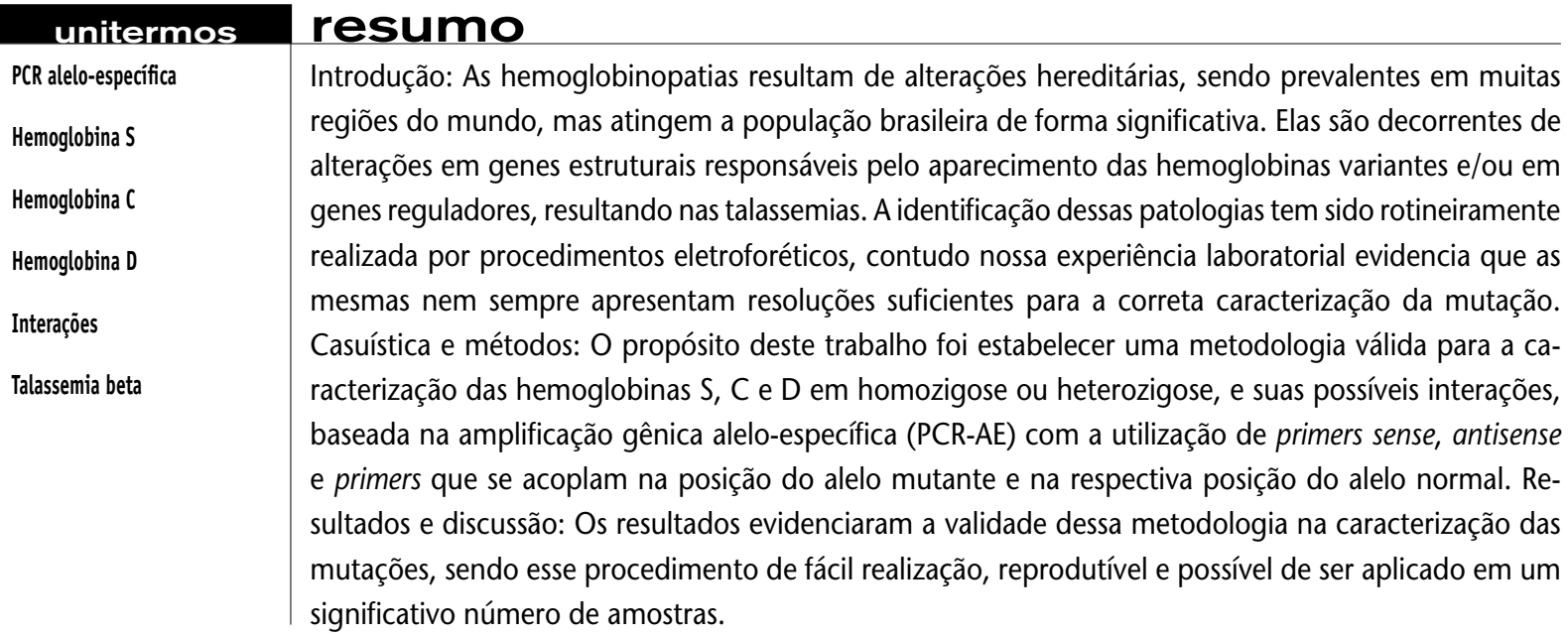

abstract

Background: The hemoglobinopathies are a group of hereditary hemoglobin disorders in worldwide distribution, affecting Brazilian population significantly; they are decurrent of alterations in structural genes, responsible for hemoglobin variants, and/or in regulatory genes, resulting the thalassemia. These disorders have been identified in most cases by electrophoretics procedures, and our laboratory experience points out that sometimes they do not obtain enough resolution for a right characterization of mutation. Material and method: The objective of this study was to establish a valid laboratory methodology for the characterization of hemoglobins S, C and D in homozygous or heterozygous and possible interactions, based on the allele-specific genic amplification (PCR-AE) with the use in parallel two primers that differ at their $3^{\prime}$ extremities and are complementary to the normal or mutated sequences. Results and discussion: The results make evident the validation of this methodology in the characterization of these mutations, once this procedure is easy to execute, to reproduce, as well as it is possible to be applied to a significative number of samples. 


\section{Introdução}

As hemoglobinopatias são decorrentes de alterações estruturais ou reguladoras nos genes da globina humana, seja quando não há produção de cadeia e/ou quando pequenas quantidades de cadeias são estruturadas, ocorrendo também interações entre hemoglobinas variantes e talassemias. Essas alterações, em sua maioria, são representadas por mutações de ponto em um único nucleotídeo, podendo ainda ser originadas por microinserções ou microdeleções, deleções ou crossing over desigual entre cromátides parentais ${ }^{(11,20)}$.

O alto grau de mistura racial apresentado pela população brasileira resultante da imigração inicial dos escravos e colonizadores, bem como da intensa miscigenação ocorrida entre eles e os nativos, propiciou características antropológicas próprias de nossa população. Nesse contexto, doenças genéticas foram preservadas e transmitidas, e entre elas as hemoglobinopatias apresentam freqüências variáveis na dependência das diversidades formadoras da população analisada ${ }^{(16,27)}$.

Na população brasileira podemos observar mais comumente alterações representadas pelas hemoglobinas $(\mathrm{Hb}) \mathrm{S}$, $\mathrm{Hb} \mathrm{C}$, beta e alfa talassemias, nas suas formas heterozigotas, sendo que as homozigotas ou duplo heterozigotas, $\mathrm{como} \mathrm{Hb}$ $\mathrm{S} / \mathrm{Hb} \mathrm{C}, \mathrm{Hb} \mathrm{S} / \beta$-talassemia, $\mathrm{Hb} \mathrm{S} / \alpha$-talassemia e $\mathrm{Hb} \mathrm{C} / \beta$-talassemia, não apresentam porcentagens expressivas ${ }^{(6,16,27)}$.

Essas patologias são rotineiramente identificadas por procedimentos eletroforéticos, mas nossa experiência laboratorial tem mostrado que esses procedimentos nem sempre apresentam resoluções suficientes para a correta caracterização de algumas mutações, como a interação da $\mathrm{Hb} \mathrm{C}$ com a talassemia beta heterozigota. Por sua vez, as metodologias moleculares demonstram validade na identificação precisa de uma mutação ou um defeito genético e várias técnicas têm sido utilizadas, como análise de Southern blot com uso de enzimas de restrição, sondas oligonucleotídeas alelo-específicas (ASOs), reação em cadeia da polimerase (PCR), amplificação gênica alelo-específica e seqüenciamento gênico ${ }^{(5,8,10,17,18,21,24,25)}$.

Portanto, o propósito deste trabalho foi estabelecer uma metodologia válida para a caracterização das hemoglobinas $\mathrm{S}, \mathrm{C}$ e D, em homozigose ou heterozigose, e interações entre elas e talassemias do tipo beta, com base nas amplificações gênica alelo-específica (PCR-AE) e na gênica multiplex (PCRmultiplex), utilizando-se primers que estrategicamente se acoplam na posição dos alelos mutante e normal alterados por somente um nucleotídeo.

\section{Casuística e métodos}

As amostras para estudo eram material genético de portadores de hemoglobinopatias de nosso interesse, que inicialmente apresentavam alterações em seu perfil eletroforético, e foram coletadas do próprio indivíduo da pesquisa e/ou obtidas de banco de amostras.

Os participantes (de ambos os sexos) tinham diferentes idades e características raciais (caucasóides e não-caucasóides) e pertenciam às diversas classes econômicas.

O projeto de pesquisa foi aprovado pelo Comitê de Ética em Pesquisa da Universidade Estadual Paulista (UNESP), Faculdade de Ciências Farmacêuticas de Araraquara, e desenvolvido obedecendo aos princípios éticos estabelecidos na Resolução 196/96 do Conselho Nacional de Saúde (CNS), sob protocolo número 15/2003.

O DNA genômico foi obtido a partir de sangue total pelo método de Miller et al.(13) modificado, baseado em precipitação do material genético por cloreto de sódio ( $\mathrm{NaCl}$ ) 6M. No material extraído verificou-se a pureza e a quantificação espectrofotométrica ${ }^{(1)}$.

Na determinação dos genótipos AA, AS, SS, AC, CC e SC utilizamos três tubos para cada amostra de DNA, sendo a reação de PCR-AE baseada no protocolo de FischelGhodisian et al. ${ }^{(10)}$ com algumas modificações de nosso laboratório e realizada para um volume final de $100 \mu \mathrm{l}$ de reação acrescentando $20 \mathrm{mmol} / \mathrm{l}$ de tampão, $0,2 \mathrm{mmol} / \mathrm{l}$ de cada dNTP; $1,5 \mathrm{mmol} / \mathrm{l}$ de $\mathrm{MgCl}_{2} ; 1,25 \mathrm{U}$ de Taq DNA polimerase (Gibco-BRL); 50 a 100ng de DNA genômico e $0,2 \mu \mathrm{mol} / \mathrm{l}$ de cada primer, sendo no tubo 1 adicionados os primers beta $5^{\prime}$-a (5' - GTA CGG CTG TCA TCA CTT AGA CCT CA - $\left.3^{\prime}\right)$, beta $5^{\prime}$-b ( $5^{\prime}$ - AGG GGA AAG AAA ACA TCA A - $\left.3^{\prime}\right)$ e beta A-b (5' - TAA CGG CAG ACT TCT CCT C - 3'); no tubo 2 os primers beta $5^{\prime}$-a, beta $5^{\prime}-\mathrm{b}$ e beta C-b (5' - TAA CGG CAG ACT TCT CCT T - 3'); e no tubo 3 primers beta $5^{\prime}$-a, beta $5^{\prime}$-b e beta S-b (5' - TAA CGG CAG ACT TCT CCA C - 3') (Figura 1).

O processo de amplificação foi realizado por uma desnaturação prévia de $95^{\circ} \mathrm{C}$ por cinco minutos, acrescida de 35 ciclos de $94^{\circ} \mathrm{C}$ por um minuto, $55^{\circ} \mathrm{C}$ por um minuto, $65^{\circ} \mathrm{C}$ por dois minutos, e seguida de uma extensão final a $65^{\circ} \mathrm{C}$ por cinco minutos.

Na identificação do genótipo $A A, A D$ e $D D$, a reação de PCR-AE foi realizada segundo Sanchaisuriya et al. ${ }^{(19)}$ modificado, utilizando-se dois tubos para cada amostra de DNA. A reação ocorreu em um volume final de $100 \mu \mathrm{l} \mathrm{com} 10 \mathrm{mmol} / \mathrm{l}$ de tampão; $0,2 \mathrm{mmol} / \mathrm{l}$ de cada desorribonuleotídeo trifosfatado (dNTP); $3 \mathrm{mmol} / / \mathrm{de}^{\mathrm{MgCl}}{ }_{2} ; 1 \mathrm{U}$ de Taq DNA polimerase 
(Gibco-BRL); 50 a 100ng de DNA genômico; e 0,2umol/l de cada primer, a saber: G7 (5' - GAT ACA ATG TAT CAT GCC TCT - 3'), G30 (5' - TGC ACT GGT GGG GTG AAT TC - 3') e H5 (5' - GCA GCC TCA CCT TCT TTC ATG G - 3') no tubo 1 e no segundo tubo os primers G7, G40 (5' - TGC ACT GGT GGG GTG AAT TG - 3') e H5 (Figura 2).

O processo de amplificação foi realizado por uma desnaturação prévia de $94^{\circ} \mathrm{C}$ por quatro minutos, acrescida de 30 ciclos de $93^{\circ} \mathrm{C}$ por 45 segundos, $60^{\circ} \mathrm{C}$ por 45 segundos, $72^{\circ} \mathrm{C}$ por um minuto e extensão final a $72^{\circ} \mathrm{C}$ por quatro minutos.

Para a identificação do genótipo SD realizou-se a reação de PCR-multiplex em um único tubo, adaptada conforme Fischel-Ghodisian et al. ${ }^{(10)}$ e Sanchaisuriya et al. ${ }^{(19)}$. A reação ocorreu em um volume final de $100 \mu \mathrm{l} \mathrm{com} 10 \mathrm{mmol} / \mathrm{l}$ de tampão; $0,2 \mathrm{mmol} / \mathrm{l}$ de cada dNTP; $3 \mathrm{mmol} / \mathrm{l}$ de $\mathrm{MgCl}_{2}$; 1,25U de Taq DNA polimerase (Gibco-BRL); 50 a 100ng de DNA genômico; e 0,2 $\mu \mathrm{mol} / \mathrm{l}$ de cada primer, a saber: beta 5 '-a, beta S-b, G7, G40 e H5 (Figura 3).
O processo de amplificação foi realizado por uma desnaturação prévia de $95^{\circ} \mathrm{C}$ por cinco minutos, acrescida de 32 ciclos de $94^{\circ} \mathrm{C}$ por 45 segundos, $57^{\circ} \mathrm{C}$ por 45 segundos, $72^{\circ} \mathrm{C}$ por um minuto e extensão final a $72^{\circ} \mathrm{C}$ por quatro minutos.

Os genótipos das interações $C / \beta^{+}$talassemia e $S / \beta^{+}$talassemia foram detectados através de protocolo adaptado de Fischel-Ghodisian et al. ${ }^{(10)}$ e Bienvenu et al. ${ }^{(4)}$, utilizando-se dois tubos para cada amostra de DNA. A reação de PCR foi realizada para um volume final de $100 \mu \mathrm{l}$ de reação com $10 \mathrm{mmol} / \mathrm{l}$ de tampão; $0,2 \mathrm{mmol} / \mathrm{l}$ de cada dNTP; $2,5 \mathrm{mmol} / \mathrm{I}$ de $\mathrm{MgCl}_{2} ; 1,25 \mathrm{U}$ de Go Taq DNA polimerase (Promega); 50 a 100ng de DNA genômico; e $0,2 \mu \mathrm{mol} / \mathrm{l}$ de cada primer, sendo no tubo 1 adicionados os primers PCO1 (5' - GTC CAA CTC CTA AGC CAG TG - 3'), PCO9 (5' - CAG ATA CCC TGG GAA CTA CA - 3'), TB110M (5' - GGG TGG GAA AAT AGA $\mathrm{CT}-3^{\prime}$ ) e beta $\mathrm{C}-\mathrm{b}$; e no tubo 2 os mesmos primers, com a substituição do beta C-b pelo beta S-b (Figura 4).

O processo de amplificação foi realizado por uma desnaturação prévia de $95^{\circ} \mathrm{C}$ por cinco minutos, acrescida de

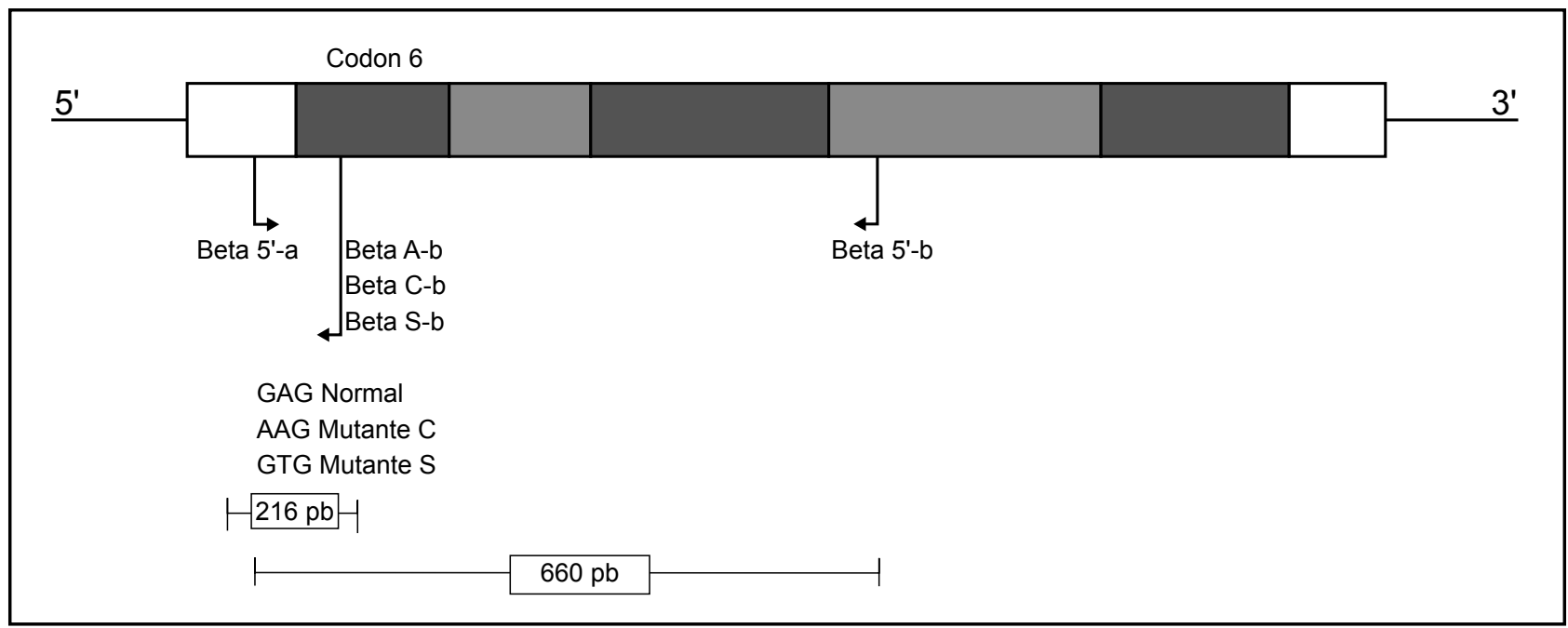

Figura 1 - Representação esquemática da localização dos primers no gene da globina beta humana na caracterização molecular das hemoglobinas S, C e interações

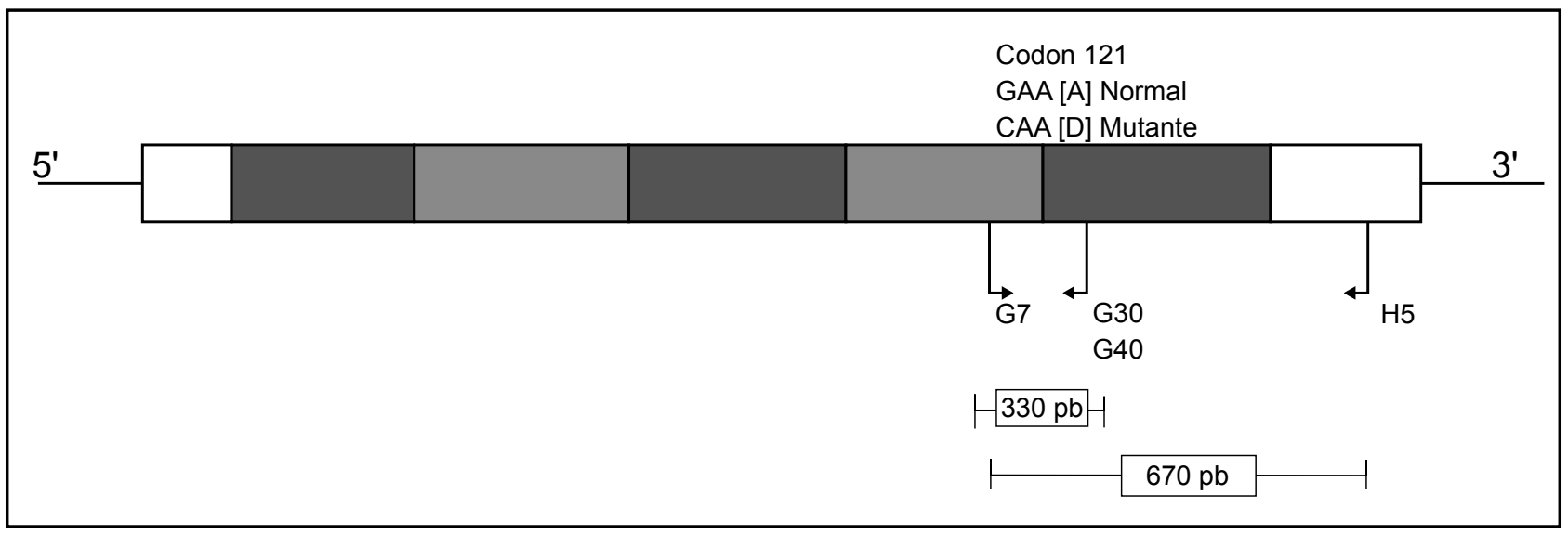

Figura 2 - Representação esquemática da localização dos primers no gene da globina beta humana na caracterização molecular da hemoglobina $D$ 


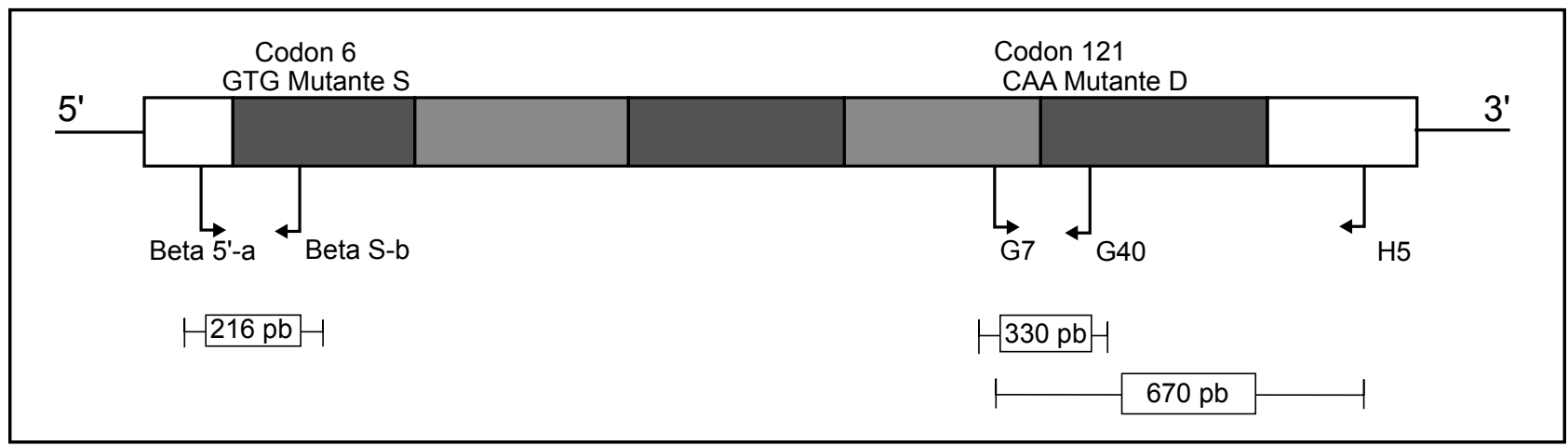

Figura 3 - Representação esquemática da localização dos primers no gene da globina beta humana na caracterização molecular da hemoglobina SD

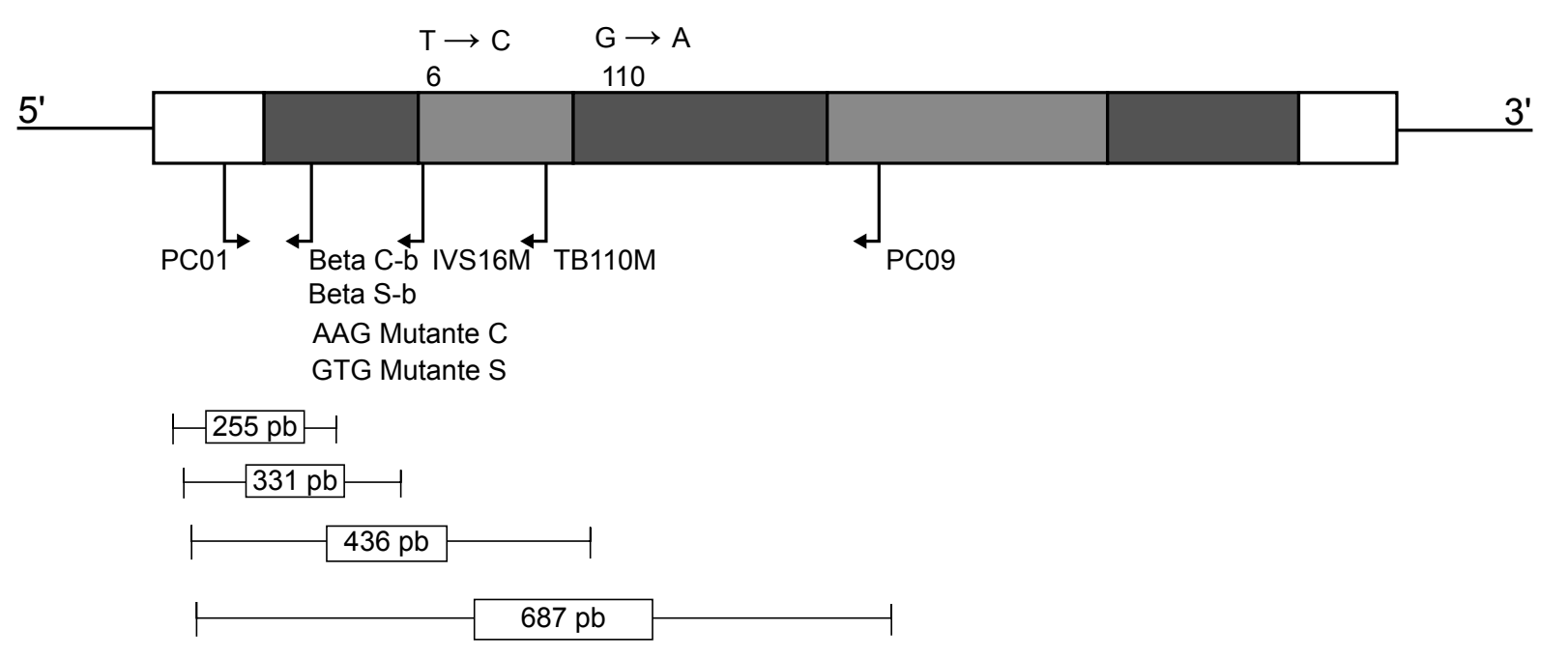

Figura 4 - Representação esquemática da localização dos primers no gene da globina beta humana na caracterização molecular da interação C/ $\beta^{+}$talassemia e S/ $\beta^{+}$talassemia

32 ciclos de $94^{\circ} \mathrm{C}$ por um minuto, $55^{\circ} \mathrm{C}$ por um minuto, $72^{\circ} \mathrm{C}$ também por um minuto, e seguida de uma extensão final a $72^{\circ} \mathrm{C}$ por cinco minutos.

Para a identificação da interação das hemoglobinas variantes com a talassemia beta IVSI-6, a reação de PCR-AE foi realizada nas mesmas condições referidas, com pequenas alterações: utilização de primers PCO1, PCO9, IVSI6M (5' - GTC TTG AAC CTT GAT G - 3') e Beta C-b e PCO1, PCO9, IVSI6M e beta S-b no segundo tubo (Figura 4). No processo de amplificação a temperatura de hibridização foi de $54^{\circ} \mathrm{C}$, realizando-se também 32 ciclos.

As análises dos produtos amplificados foram verificadas em gel de agarose a $2 \%$, evidenciadas com brometo de etídio e visualizadas sob transluminador.

As reações de amplificação foram realizadas no termociclador MiniCycler' ${ }^{\mathrm{TM}}$ da MJ Research, conforme algoritmo estabelecido para o equipamento, e na dependência do fragmento de DNA a amplificar e das temperaturas de fusão (Tm) dos primers utilizados.

\section{Resultados}

Na determinação dos genótipos AA, AS, SS, AC, CC e SC, observou-se como produto de amplificação uma banda de $660 \mathrm{pb}$, que caracterizava a validade e efetividade da reação, representando o controle positivo da mesma e devendo estar presente nos três tubos, enquanto uma banda de $216 \mathrm{pb}$ aparece na dependência do primer utilizado, o que permitiu caracterizar os diferentes genótipos.

Para a verificação do genótipo $D$ utilizamos dois tubos de reações: quando o genótipo era normal observamos no tubo 1 bandas de 670 e $330 \mathrm{pb}$, e no tubo 2 uma banda de $670 \mathrm{pb}$; quando heterozigoto aparecia em ambos os tubos, bandas de 670 e $330 \mathrm{pb}$, e quando homozigoto mutante, no tubo 1 visualizava-se uma banda de 670pb e no tubo 2 as bandas de 670 e $330 \mathrm{pb}$.

Na caracterização dos genótipos SD, observou-se como produto de amplificação uma banda de $670 \mathrm{pb}$, como o controle positivo da reação, uma banda de $330 \mathrm{pb}$ representando o genótipo D e outra de $216 \mathrm{pb}$ para o genótipo $S$, 
caracterizando assim a interação SD. Se apenas a banda de 330 ou de $216 \mathrm{pb}$ fosse visualizada, outra PCR deveria ser realizada, de acordo com os protocolos padronizados, a fim de caracterizar a homozigose ou heterozigose para a mutação em questão.

Os genótipos $C / \beta^{+}$talassemia e $S / \beta^{+}$talassemia foram caracterizados pela observação de uma banda de $687 \mathrm{pb}$, como o controle positivo da reação, enquanto uma banda de $436 \mathrm{pb}$ representava o genótipo de IVS I-110, e outra de 331 pb o genótipo IVS I-6, na dependência do tubo em que ocorria a reação; uma banda de $255 \mathrm{pb}$ representava o genótipo $C$ ou $S$, também na dependência do tubo da reação. Nessa PCR identificamos o duplo heterozigoto e se apenas uma das mutações for evidenciada, deve-se realizar os protocolos padronizados para caracterizar o homozigoto ou o heterozigoto para a mutação em questão.

\section{Discussão}

O diagnóstico de hemoglobinas variantes pode ser realizado, entre diversas técnicas laboratoriais, por procedimentos eletroforéticos, como a eletroforese em acetato de celulose alcalina, a eletroforese em ágar citrato ou fosfato ácido, a focalização isoelétrica em gel constituído por acrilamida ou agarose em diferentes $\mathrm{pHs}$, e por cromatografia líquida de alta eficiência, entre outros ${ }^{(3,12)}$.

De acordo com o US Department of Health and Human Services ${ }^{(23)}$ a verificação de alterações no gene $S$ deve necessariamente incluir procedimentos que permitam o encontro de suas formas comuns, a saber: $\mathrm{Hb}$ AS, $\mathrm{Hb} \mathrm{SS}, \mathrm{Hb} \mathrm{SC}$ e interações - o mesmo se aplica para a identificação do gene $C$.

$\mathrm{Na}$ identificação por metodologia molecular vários autores relatam o uso de oligonucleotídeos alelo-específicos (ASOs) e PCR seguida de restrição enzimática para a verificação de alterações na molécula de hemoglobinas $S$ e C, e interações ${ }^{(5,21)}$. Neste trabalho essas foram caracterizadas por reação em cadeia da polimerase alelo-específica (PCR-AE), permitindo a detecção direta do alelo normal ou mutante no DNA genômico, sem provas adicionais de hibridização, ligação ou clivagem com enzima de restrição ou o uso de radioatividade.

Através da PCR-AE foi possível distinguir os alelos mutantes $\mathrm{Se} C$ heterozigotos e homozigotos, além de diferenciálos do alelo normal e do duplo heterozigoto SC.

Postnikov et al. ${ }^{(17)}$ realizaram a PCR-AE para a diferenciação entre os genótipos AS e SS, mostrando que esse procedimento é importante no diagnóstico rápido de homozigoto para $\mathrm{Hb} \mathrm{S}$ e para pacientes com a interação $\mathrm{Hb}$ S/beta talassemia, sendo necessárias condições de anelamento estritas para que a reação ocorresse.

Um método rápido para diagnóstico diferencial de $\mathrm{Hb}$ S e outras variantes, como $\mathrm{Hb} \mathrm{D}$ e Hb Tak, foi desenvolvido e validado, usando PCR-AE-multiplex para facilitar o programa de triagem de hemoglobinopatias na população asiática ${ }^{(19)}$.

Em nosso trabalho, padronizamos a identificação do duplo heterozigoto S/D também através de PCR-multiplex. Os bons resultados obtidos permitiam verificar a validade dessa metodologia e sua possível utilização em rotina laboratorial.

A mutação beta $S$ pode ser detectada por PCR-AE ou análise de PCR-RFLP com endonuclease de restrição Mst II. Também se pode identificar a $\mathrm{Hb}$ D Punjab através de PCR-RFLP com a enzima de restrição EcoRI, bem como por PCR-AE ${ }^{(19)}$, parecendo essa última mais prática na rotina laboratorial.

Outros estudos realizados mostram que o genótipo $D$ pode ser detectado principalmente por seqüenciamento direto do produto da PCR, RFLP e análise de Southern blot ${ }^{(1,9)}$, podendo também ser identificado por PCR-AE-multiplex, prática não muito comum em nosso país e que realizamos no presente trabalho, evidenciando validade expressiva.

Na nossa população, a ocorrência de Hb D Los Angeles foi relatada por Zago e Costa ${ }^{(26)}$ em quatro famílias brasileiras, em estado de heterozigose, duplo heterozigoto $\mathrm{Hb} D / \beta^{+}$ talassemia e interação $\mathrm{Hb} \mathrm{S/Hb} \mathrm{D}$, sendo essas associações descritas também em vários países.

Naoum et al. ${ }^{(15)}$ também demonstraram a interação entre $\mathrm{Hb} \mathrm{D}$ e talassemia beta num indivíduo brasileiro e em seus familiares. A identificação da interação $\mathrm{Hb} \mathrm{S/Hb} \mathrm{D}$ por amplificação gênica multiplex poderia facilitar o diagnóstico desse duplo heterozigoto, que não é efetivo por eletroforese em acetato de celulose como em ágar ácido.

Em um estudo realizado na população portuguesa foram analisados os haplótipos do gene da globina beta e caracterizadas as mutações para as talassemias beta, por hibridização oligonucleotídea, em 14 pacientes com talassemia beta maior e cinco com interação $\mathrm{Hb}$ S/beta talassemia originários do sudeste de Portugal. Destacam-se como prevalentes três mutações, a saber: CD 39, IVS I-1 e IVS I-110 com porcentagens de $53 \%$, 32\% e $10 \%$, respectivamente ${ }^{(7)}$. Por sua vez, a IVS I-6 também foi identificada, com relativa freqüência, na população da região nordeste de Portugal(22).

Num levantamento realizado em nosso laboratório, na população brasileira da região central do Estado de São Paulo observamos nas mutações beta talassêmicas, $65,1 \%$ do CD 39; $18,6 \%$ de IVS I- $110 ; 9,3 \%$ de IVS I- 1 ; e $4,7 \%$ para 
IVS I-6, sendo essa distribuição semelhante às observadas no norte da Itália ${ }^{(14)}$.

Ao considerar a possibilidade de identificar alterações nos genes $S$ e $C$ pelo método de PCR-AE, a verificação de interações dos mesmos também foi viabilizada, estabelecendo-se a metodologia necessária. Os primers utilizados para a identificação dos genótipos $S$ e $C$ associados aos usados para talassemia beta, no caso IVS I-6 e IVS I-110, proporcionaram por PCR-AE a resolução da interação $\mathrm{Hb}$ $\mathrm{S} / \beta^{+}$talassemia e $\mathrm{Hb} C / \beta^{+}$talassemia, mostrando essa técnica ser importantíssima no diagnóstico dessas interações.

\section{Conclusão}

Devido à importância das hemoglobinas variantes, com interações na população brasileira, e à dificuldade na inves- tigação de algumas delas, a partir das análises laboratoriais convencionais, foi possível padronizar um teste diagnóstico baseado na amplificação gênica alelo-específica (PCR-AE) e na amplificação gênica multiplex (PCR-multiplex).

Assim, evidenciamos a necessidade do estabelecimento de protocolos de aplicação laboratorial, com a utilização da reação em cadeia da polimerase alelo-específica e da multiplex, na identificação de estados homozigotos, heterozigotos e interações.

\section{Agradecimentos}

Os autores agradecem o apoio recebido da Fundação para o Desenvolvimento da Unesp (FUNDUNESP) pelo auxílio financeiro concedido para o desenvolvimento da pesquisa.

\section{Referências}

I. ABDEL-RAHMAN, S.Z. Isolation of DNA using salting-out procedure.J Biochem Toxicol, v. 9, p. 191-8, 1994.

2. AKAR, N. et al. Discrimination of Hb D Los Angeles (BI2I Glu$\mathrm{Gln}$ ) and $\mathrm{Hb}$ Beograd (BI2I Glu-Val) by dual restriction enzyme analysis. Am J Hematol, v. 48, p. 280-I, 1995.

3. BASSET, P.; BRACONNIER, F.; ROSA, J. An update on electrophoretic and chromatographic methods in the diagnosis of hemoglobinopathies. J Chromatogr, v. 227, p. 267-304, 1982.

4. BIENVENU, T. et al. Rapid and direct detection of the most frequent Mediterranean $\beta$-thalassemic mutations by multiplex allele-specific enzymatic amplification. Human Biology, v. 64, n. I, p. 107-13, 1992.

5. CLARKE, G.M.; HIGGINS, T.N. Laboratory investigation of hemoglobinopathies and thalassemias: Review and update. Clin Chem, v. 46, n. 8, p. 1284-90, 2000.

6. COSTA, F.F. Biologia molecular: métodos básicos. Boletim UNICAMP, v. 13, n. I56, p. 8-9, 1991.

7. COUTINHO GOMES, M.P. et al. B-thalassemia mutations in the Portuguese population. Hum Genet, v. 78, p. 13-15, 1988.

8. FIGUEIREDO, M.S. et al. Effect of $\alpha$-thalassemia and $\beta$-globin gene cluster haplotypes on the hematological and clinical features of sickle-cell anemia in Brazil. Am J Hematol, v. 53, p. 72-6, 1996.

9. FIORETTI, G. et al. DNA polymorphisms associated with Hb D Los Angeles [ $\mathrm{Bl} 2 \mathrm{I}(\mathrm{GH} 4) \mathrm{GLU} \rightarrow \mathrm{GLN}]$ in southern Italy. Hemoglobin, v. 17, n. I, p. 9-17, 1993.

10. FISCHEL-GHODISIAN, N.; HIRSCH, P.C.; BOHLMAN, M.C. Rapid detection of the hemoglobin $C$ mutation by allelespecific polymerase chain reaction. Am J Hum Genet, v. 47 , p. $1023-4,1990$.
I I. HONIG, G.R.;ADAMS III,J.G. Human hemoglobin genetics. Wien: Springer-Verlag; 1986.452p.

12. MARIO, N. et al. Capillary isoelectric focusing and highperformance cation-exchange chromatography compared for qualitative and quantitative analysis of hemoglobin variants. Clin Chem, v. 43, p. 2 I 37-42, 1997.

13. MILLER, S.A.; DYKES, D.D.; POLESKY, H.F. A simple salting out procedure for extracting DNA from human nucleated cells. Nucleic Acids Research, v. 16, n. 3, p. 1215, 1988.

14. MOREIRA, H.W. Diagnóstico molecular das talassemias do tipo beta por amplificação gênica (PCR) e eletroforese em gradientes desnaturantes (DGGE). News Lab, v. I5, p. 85-94, 1996.

15. NAOUM, P.C. et al. Hb D/Talassemia beta associada à anemia crônica. Rev Bras Hematol Hemoter, v. 23, n. I, p. 5I-2, 2002.

16. PAIVA E SILVA, R.B.; RAMALHO, A.S.; CASSORLA, R.M. A anemia falciforme como problema de saúde pública no Brasil. Rev Saúde Pública, v. 27, p. 54-8, 1993.

17. POSTNIKOV, Y.V.; MOLCHANOVA, T.P.; HUISMAN, T.H.J. Allele-specific amplification for the identification of several hemoglobin variants. Hemoglobin, v. 17, n. 5, p. 439-52, 1993.

18. SAIKI, R.K. et al. Primer-directed enzymatic amplification of DNA with a thermostable DNA polymerase. Science, $v$. 239, p. 487-9I, 1988.

19. SANCHAISURIYA, K. et al. Multiplex allele-specific PCR assay for differential diagnosis of $\mathrm{Hb} \mathrm{S}, \mathrm{Hb}$ D-Punjab and $\mathrm{Hb}$ Tak. Clin Chim Acta, v. 343, p. 129-34, 2004.

20. SIGURET, V.; ANDREUX, J.P. Biological diagnosis of haemoglobinopathies by phenotype analysis. Ann Biol Clin, v. 55, p. 103-12, 1997. 
21. STUDENCKI, A.B. et al. Discrimination among the human $\beta^{A}$, $B^{S}$ and $B^{C}$ globin genes using allele-specific oligonucleotide hybridization probes. Am J Hum Genet, v. 37, p. 42-5I, 1985.

22.TAMAGNINI, G.P. et al. $\beta^{+}$-thalassemia portuguese type: clinical, haematological and molecular studies of a newly defined form of ß-thalassemia. Br J Haematol, v. 54, p. I89-200, 1983.

23. US DEPARTMENT OF HEALTH AND HUMAN SERVICES. Guideline: laboratory screening for sickle cell disease. Lab Med, v. 24, p. 515-22, 1993.
24.WATERFALL, C.M.; COBB, B.D. Single tube genotyping of sickle cell anaemia using PCR-based SNP analysis. Nucleic Ac Res, v. 29(23), p. I-8, 200I.

25.WU, D.Y. et al.Allele-specific enzymatic amplification of ß-globin genomic DNA for diagnosis of sickle cell anemia. Proc Nat Acad Sci USA, v. 86, p. 2757-60, 1989.

26. ZAGO, M.A.; COSTA, F.F. Hb D Los Angeles in Brazil: Simple heterozygotes and associations with $B$ thalassemia and with Hb S. Hemoglobin, v. 12, n. 4, p. 399-403, 1988.

27. ZAGO, M.A.; COSTA, F.F. Hereditary hemoglobin disorders in Brazil. Trans Roy Soc Trop Med Hyg, v. 79, p. 385-8, 1985. 